\title{
Análise das práticas do Lean Construction em um empreendimento residencial
}

\section{Jéssica Pereira Santos Spósito}

Engenheira Civil graduada no Centro Universitário Metodista Izabela Hendrix jejpereira@hotmail.com

Vanini Dutra Perdigão

Engenheira Civil graduada no Centro Universitário Metodista Izabela Hendrix vaninidutra@yahoo.com.br

Renato Vieira Barbosa

Engenheiro de Produção Civil pela Universidade FUMEC. Diretor de construção na Neocasa Brasil renatovieirabarbosa@gmail.com

Pedro Rocha Galvão Junior

Engenheiro Civil pela Universidade Federal de Minas Gerais. Professor Universitário e de cursos de Especialização em Gestão de Projetos (MBA).

pedrogalvaojr@hotmail.com

\section{Editor Científico: José Edson Lara}

Organização Comitê Científico

Double Blind Review pelo SEER/OJS

Recebido em 03.01.2017

Aprovado em 27.02.2018

\footnotetext{
(c) (i) (8)

Este trabalho foi licenciado com uma Licença Creative Commons - Atribuição - Não Comercial 3.0 Brasil
} 


\title{
Resumo
}

São inúmeras as razões para se estudar a metodologia Lean, dentre elas o fato de que o conceito não está aliado somente às escalas de produção e setores da economia. Ela visa à satisfação total do cliente, sem que ele tenha que pagar pelas falhas e desperdícios que ocorrem durante os processos envolvidos. O presente artigo possui como objetivo avaliar a implementação da filosofia de planejamento Lean Construction em diferentes etapas de uma obra, identificando, de forma crítica, o desenvolvimento de todos os processos da obra. Para tanto, realizou-se uma pesquisa quantitativa e qualitativa, resultando assim uma análise entre a metodologia aplicada em uma obra e a filosofia da construção enxuta. Os resultados obtidos sugerem que a implantação desta filosofia foi proficiente no âmbito de atender às necessidades do empreendedor e do cliente, nas expectativas de controle de custo, cumprimento dos prazos estabelecidos inicialmente e garantia da qualidade final do produto.

Palavras-chave: Planejamento; Construção Enxuta; Produtividade; Prazo; Custos.

\section{Analysis of Lean Construction Practices in a residential enterprise}

\begin{abstract}
There are many reasons to study the Lean methodology, among them is that the concept is not only ally to production scales and sectors of the economy. It aims to complete customer satisfaction, without having to pay for the failures and waste that occur during the processes involved. This article aims to evaluate the implementation of Lean Construction planning philosophy at different stages of the work, identifying, critically, the development of all work processes. Therefore, we carried out a quantitative and qualitative research, performing an analysis between the methodology applied in a work and the philosophy of lean construction. These results suggested that the implementation of this philosophy, was proficient in the context of meeting the needs of the entrepreneur and the customer, the cost control expectations, compliance with the deadlines and ensuring final product quality.
\end{abstract}

Keywords: Planning; Lean Construction; Productivity; Time; Costs. 


\section{Resumen}

Existen innumerables motivos para estudiar la metodología Lean, entre ellos el hecho de que el concepto no es aliado sólo a las escalas de producción y sectores de la economía. Es sobre la satisfacción total del cliente, sin que él tenga que pagar las fallas y desperdicios que ocurren durante los procesos involucrados. El objetivo de este artículo es evaluar la implementación de la filosofía de planificación Construcción Lean en diferentes etapas de una obra, identificando de forma crítica el desarrollo de todos los procesos de la obra. Para ello, se realizó una investigación cuantitativa y cualitativa, resultando en un análisis entre la metodología aplicada en una obra y esa filosofía de construcción. Los resultados obtenidos sugieren que la implementación de esta filosofía fue proficiente en el campo de atender a las necesidades del emprendedor y del cliente, en las expectativas de control de costos, cumplimiento de los plazos inicialmente establecidos y garantía de la calidad final del producto.

Palabras clave: Planificación; Construcción Lean, Productividad; Plazos; Costes.

\section{Introdução}

A engenharia civil, em todo o tempo, foi objeto de críticas, em virtude especialmente dos altos custos (desperdício) e baixa produtividade, esclarece Lorenzon e Martins (2006). São perceptíveis as mudanças e as crescentes pressões que o mercado da construção civil vem sofrendo, passando a buscar menores custos, melhoria na qualidade e nos processos de produção (Sales, Barros \& Almino, 2004).

A concorrência é um elemento muito significativo, tanto em mercados externos quanto no mercado nacional (Ballou, 2006). Em uma época na qual a palavra qualidade é dita constantemente, é necessário que o gerenciamento da obra seja feito com o objetivo de ocorrer dentro do prazo, custo, qualidade e risco previamente estabelecidos (Limmer, 2013).

Ballou (2006) relata que as empresas aplicam o conceito da resposta rápida às suas operações internas, criando assim, uma grande vantagem de comercialização, por isso, se faz necessário em alguns casos modificar a rede existente dentro da empresa. Uma das formas mais produtivas de se conseguir um considerável nível de objetividade em uma organização é diminuir as ineficácias da produtividade, estas que são consideradas fontes de ausência de gestão, prejudicando os resultados. (Costa \& Luiz, 2008).

Muitas obras ainda são executadas com um planejamento informal, sem a garantia do cumprimento do prazo estabelecido e, muito menos, do orçamento 
(Limmer,2013). É fundamental, portanto, responder de forma rápida às mudanças competitivas no mercado, desenvolvendo e implementando estratégias com rapidez e exatidão necessárias para fazer a diferença (Azevedo, Barros, \& Nunes, 2010).

Diante disso, entidades de construção civil estão se baseando no sistema Lean Construction, ou seja, construção enxuta. O pensamento Lean possui como objetivo principal a eliminação de desperdício, seja ele material ou humano, aplicando-se assim ferramentas e técnicas de controle da qualidade, aperfeiçoando a produção (Tonin \& Schaefer, 2013). Esta produção é baseada no estilo desenvolvido pela Toyota e é caracterizada por utilizar quantidades mais baixas em tudo, se comparada à produção em massa (Sales, Barros \& Almino, 2004).

São inúmeras as razões para se estudar a metodologia Lean, entre elas o fato de que o conceito não está aliado às escalas de produção e setores da economia, além de outros fatores, pois ela consiste numa proposta de mentalidade diferente, visando a satisfação total do cliente, sem que ele tenha que pagar pelas falhas e desperdícios que ocorrem durante os processos envolvidos. Por isso, estudar todas as ferramentas envolvidas e a filosofia Lean é importante, pelo fato de essa poder ser aplicada em todas as áreas da empresa, priorizando aquelas em que exista maior quantidade de desperdícios, oferecendo a essas áreas maiores oportunidades de melhoria (LEAN INSTITUTE BRASIL, 2016).

Tomando como base estas afirmações, este artigo tem o objetivo de apresentar um estudo de caso que permitirá identificar de forma clara e objetiva a utilização do pensamento Lean em um empreendimento do programa Minha Casa, Minha Vida, no estado de Minas Gerais. Portanto, a partir da discussão apresentada anteriormente, o artigo oferece uma alternativa viável para planejamento e controle de obras, porém se faz necessário o seguinte questionamento: o sistema Lean Construction otimizará os processos em uma obra que necessita de cumprimento de prazos, controle dos custos e garantia da qualidade?

\section{Referencial Teórico}

\subsection{Lean Construction}


Em 1950, no Japão, nasceu a produção Lean, mais especificamente na Toyota Motor Company por Eiji Toyoda e Taiichi Ohno. Independentemente dos conceitos do Lean terem origem na produção, eles podem ser investidos universalmente, traduzindo, adaptando e aplicando-os de acordo com a necessidade específica de cada área. A mentalidade Lean de produção figura em produzir mais com menos menos período de tempo, menos ambiente, menos estímulo humano, menos equipamentos, menos insumos, sem deixar de levar ao cliente o que ele solicita, diminuindo assim todo e qualquer desperdício (Dennis, 2008).

Costa (2008) aborda que as empresas estão em busca permanente por alto desempenho, maleabilidade e concorrência para conseguirem focalizar redução de custos e aumento dos lucros, assim, reduzindo todas as improdutividades na produção que necessitam de ser eliminadas, pois causam falhas nos processos, na organização, e no ambiente de trabalho. O propósito apresentado pela mentalidade enxuta necessita ser deliberado com o intuito de alcançar o máximo de produtividade e eficácia, associado aos baixos custos, alcançando grau zero de defeitos, de duração na preparação, no estoque e de movimentação.

Neste contexto, o termo Lean Construction é baseado no trabalho acadêmico de Koskela realizado em 1992, chamado "Application of the new production philosophy in the construction industry" (Aplicação da nova filosofia de produção na indústria da construção), no qual ele avaliou a aplicabilidade do sistema de produção da indústria automobilística na construção civil, originando assim o termo "Construção Enxuta". Sendo assim, o Lean Construction é uma adaptação do Lean Production para a construção civil (Souza \& Cabette, 2014).

De acordo com Tonin e Schaefer (2013) o Lean Construction busca aperfeiçoar a construção, aprimorando o modelo do processo tradicional. Portanto, a construção enxuta é ir além do método tradicional de enxergar os projetos como mera transformação, pois essa nova teoria inclui tempo, variabilidade e satisfação do cliente como variáveis importantes para o processo de decisão (Wiginescki, 2009).

\subsection{O Planejamento e o Lean Construction}


O planejamento e o controle de obras em edificações devem ser considerados como um processo gerencial compartilhado com os diversos níveis gerenciais, requerendo a participação e comprometimento de todos. Não é possível planejar todos os mínimos detalhes, porém, podem-se minimizar as incertezas por meio de um controle eficaz e eficiente, levando assim à conclusão de que esta é a proposta chave do Lean Construction (Souza \& Cabette, 2014).

Portanto, a utilização do modelo de gestão Lean Construction viabiliza as diversas ferramentas convencionais de programação de obras, proporcionando benefícios para o planejamento operacional e controle físico da obra (Ferreira, 2003).

\subsection{Previsto $\times$ Realizado}

Plotando-se os pares ordenados tempo-posição do avanço real, pode-se avaliar então se o progresso da obra está além ou abaixo do previsto.

Três situações podem ocorrer ao realizar uma linha de balanço de acordo com Mattos (2010):

a) Linha do realizado condiz com a linha do previsto: o serviço está em dia.

b) Linha do realizado está em movimento ascendente da linha do previsto: 0 serviço está adiantado.

c) Linha do realizado está abaixo da linha do previsto: o serviço está em atraso.

A curva que mostra o progresso real da obra pode ficar extrapolada, fornecendo assim, a estimativa do ganho de tempo ou atraso no final do serviço, como pode ser observado na Figura 1. 


\section{Progresso}

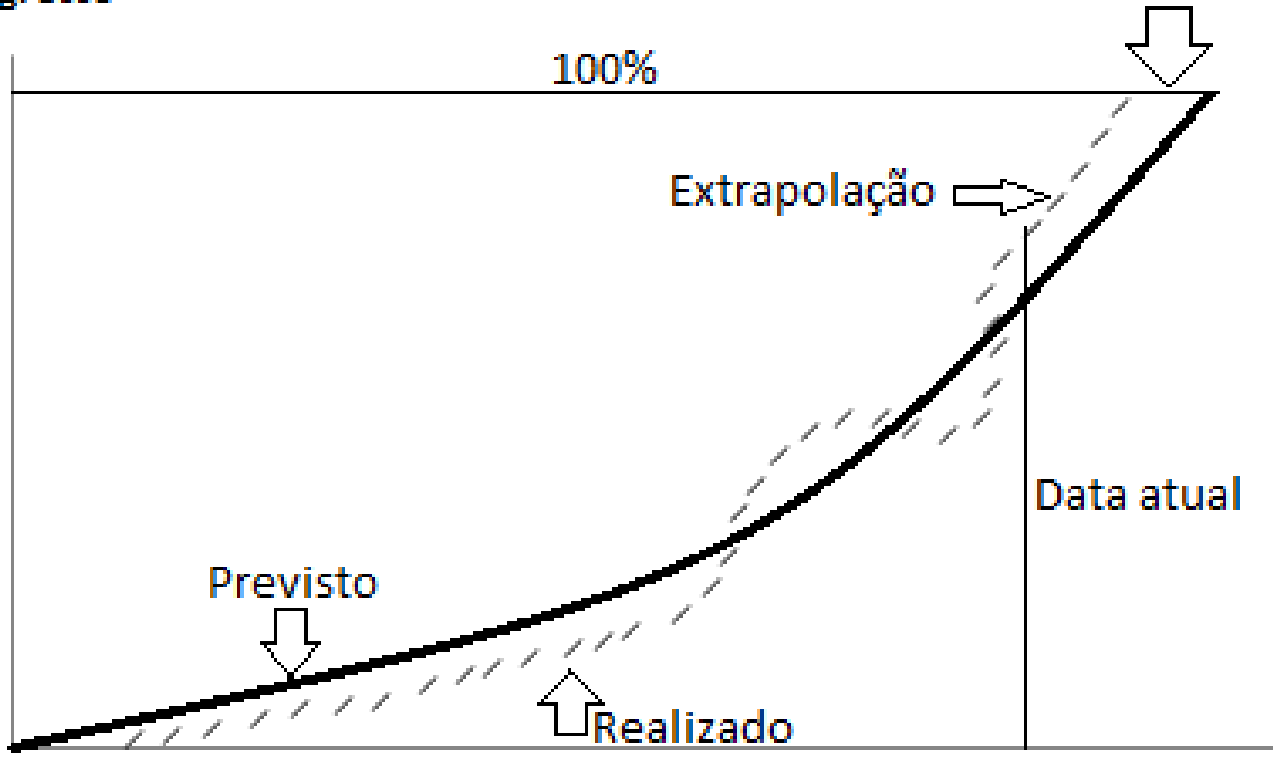

Tempo

\section{Figura 1}

Linha de Balanço

Fonte: Adaptado de Mattos (2010). Planejamento e Controle de Obras (p. 399). São Paulo: PINI LTDA.

\subsection{Controle da Obra e o Lean Construction}

Koskela (1992) afirma que o desperdício característico da construção é criado por retrabalhos devidos a erros de projetos ou de execução e a atividades que não agregam valores nos fluxos de materiais e trabalho, tais como esperas, movimentação, inspeção, atividades duplicadas e acidentes. Desse modo, o foco principal do projeto é minimizar a perda de valor, ao passo que na construção é o desperdício.

Pode-se concluir então que o Lean Construction direciona suas ações para "enxugar" todas as atividades da obra que não agregam valores e sua proposta é reduzir os custos sem precisar de investimentos, utilizando apenas uma melhor organização do processo (Barros, 2005).

\section{Metodologia}

O presente estudo teve caráter de pesquisa aplicada, pois buscou-se analisar e utilizar uma filosofia inovadora na área de planejamento e controle de obras e quanto 
ao objetivo que norteou o projeto, caracterizou-se como uma pesquisa exploratória (Gil, 2008). A técnica da pesquisa foi quantitativa e qualitativa, pois estabeleceu análises e comparações para generalização dos resultados, no sentido de quantificar os dados e apresentar respostas numéricas e analíticas. Assim, o perfil empregado na pesquisa foi um estudo de caso.

A construtora escolhida tem mais de 25 anos no mercado imobiliário e nesse período já desenvolveu mais de 100 empreendimentos nos estados de Minas Gerais, São Paulo, Rio Grande do Sul, Bahia, Pará, Maranhão e Amazonas, entregando mais de 15 mil imóveis. Entre os projetos em desenvolvimento pela construtora, foi escolhido 0 empreendimento nomeado City Divinópolis. Localiza-se aproximadamente 118 quilômetros de distância da capital mineira (Belo Horizonte), que consiste na execução de um empreendimento residencial Minha Casa, Minha Vida - Faixa 2 (destinado às famílias com renda mensal de 3 (três) a 10 (dez) salários mínimos) e é composto por 12 (doze) blocos, com 4 (quatro) pavimentos cada e 4 (quatro) apartamentos por andar, perfazendo um total de 192 (cento e noventa e duas) unidades, sendo que duas são destinadas ao espaço Gourmet. O tempo previsto de obra é de 17 (dezessete) meses, com início em 15 de abril de 2016 e término previsto em setembro de 2017. Foi avaliado o sistema de planejamento aplicado nessa obra.

Foi utilizado o embasamento teórico e prático para acompanhamento e análise da implementação da filosofia Lean Construction aplicado no canteiro da obra em diferentes etapas. Foram incluídas para complementar a pesquisa as estratégias e técnicas atribuídas ao sistema, bem como todas as atividades realizadas, de forma a delinear todo o projeto de pesquisa.

Para esta avaliação do sistema de planejamento, foram coletados os dados quantitativos e qualitativos para análise final. Os dados foram coletados mensalmente por meio de:

- $\quad$ Planejamento apresentado pelos gestores da construtora;

- $\quad$ Planilhas, gráficos, tabelas e similares;

- Visita ao campo;

- Acompanhamento do planejamento na obra;

- $\quad$ Discussões com o gestor responsável;

- Coleta de fotos no canteiro da obra. 
O principal procedimento metodológico baseou-se em análises dos resultados obtidos no comparativo entre a metodologia aplicada na obra e a filosofia Lean Construction - Construção Enxuta. As análises citadas foram adquiridas por meio de gráficos com análises físico-financeiras (previsto $\times$ realizado), bem como também de tabelas e planilhas. Foi analisado o planejamento sempre levando em consideração o previsto inicialmente pelos gestores da construtora e também, sempre em relação ao último mês de evolução de obra. Diante das análises e comparações, foi avaliado de forma geral a implementação da filosofia Lean Construction - Construção Enxuta no empreendimento, identificando se a utilização desta filosofia nessa tipologia de construção atendeu às necessidades do empreendedor e cliente no que tange aos fatores determinantes de prazo, custo e qualidade.

\section{Apresentação e Discussão dos Resultados}

Mediante o planejamento da obra em mãos, foi possível comparar os resultados da obra até o momento, com a proposta inicial da construtora. Inicialmente, como indica a Figura 2, percebeu-se que o gestor do empreendimento estabeleceu um prazo para que todas as atividades fossem executadas de forma contínua, como sugere a filosofia Lean Construction.

\begin{tabular}{|c|c|c|c|c|c|c|c|c|c|c|c|c|c|c|c|c|c|c|c|c|c|c|c|c|c|c|c|c|c|}
\hline \multirow{2}{*}{ ATIYIDADE } & \multicolumn{2}{|c|}{ sbrll6 } & \multicolumn{2}{|c|}{ nail16 } & \multicolumn{2}{|c|}{ ine/16 } & \multicolumn{2}{|c|}{ inlliti } & \multicolumn{2}{|c|}{ 290/16 } & \multicolumn{2}{|l|}{ setil16 } & \multicolumn{2}{|c|}{ ont/16 } & \multicolumn{2}{|c|}{ Lor/16 } & \multicolumn{2}{|c|}{ dez/16 } & jazll17 & fetilit & Earlit? & \multicolumn{2}{|c|}{$2 b_{r} / 177$} & \multicolumn{2}{|c|}{ asill? } & \multicolumn{2}{|c|}{ ind } & \multicolumn{2}{|c|}{ inlliti } \\
\hline & $15 \quad 3$ & 30 & $15 \quad 3$ & 30 & 15 & 30 & 15 & 30 & 15 & 30 & $15 \quad 3$ & 30 & $15 \quad 3$ & 30 & $15 \quad 3$ & 30 & $15 \quad 3$ & 30 & $15 \quad 30$ & $\begin{array}{|lr|}15 & 30 \\
\end{array}$ & $15 \quad 30$ & 15 & 30 & 15 & 30 & 15 & 30 & 15 & 30 \\
\hline Terraplanage= & & & & & & & & & & & & & & & & & & & & & & & & & & & & & \\
\hline Fudaçác & & & & & & & & & & & & & & & & & & & & & & & & & & & & & \\
\hline Cintanento con & & & & & & & & & & & & & & & & & & & & & & & & & & & & & \\
\hline Altenaria e Laje & & & & & & & & & & & & & & & & & & & & & & & & & & & & & \\
\hline Janelas e Marco & & & & & & & & & & & & & & & & & & & & & & & & & & & & & \\
\hline Reboco lnterno & & & & & & & & & & & & & & & & & & & & & & & & & & & & & \\
\hline Gesso & & & & & & & & & & & & & & & & & & & & & & & & & & & & & \\
\hline \begin{tabular}{|l|} 
Contra Piso \\
\end{tabular} & & & & & & & & & & & & & & & & & & & & & & & & & & & & & \\
\hline Cers̆nics & & & & & & & & & & & & & & & & & & & & & & & & & & & & & \\
\hline Ports & & & & & & & & & & & & & & & & & & & & & & & & & & & & & \\
\hline Forro de Gesso & & & & & & & & & & & & & & & & & & & & & & & & & & & & & \\
\hline Fiaģ́o e Cabos & & & & & & & & & & & & & & & & & & & & & & & & & & & & & \\
\hline Longas & & & & & & & & & & & & & & & & & & & & & & & & & & & & & \\
\hline \begin{tabular}{|l|} 
Pente Fino \\
\end{tabular} & & & & & & & & & & & & & & & & & & & & & & & & & & & & & \\
\hline Feclanento QDC & & & & & & & & & & & & & & & & & & & & & & & & & & & & & \\
\hline Pistura Interns & & & & & & & & & & & & & & & & & & & & & & & & & & & & & \\
\hline Interruptor \& To & & & & & & & & & & & & & & & & & & & & & & & & & & & & & \\
\hline Liopeza Fins & & & & & & & & & & & & & & & & & & & & & & & & & & & & & \\
\hline Reboco Externo & & & & & & & & & & & & & & & & & & & & & & & & & & & & & \\
\hline Telliado & & & & & & & & & & & & & & & & & & & & & & & & & & & & & \\
\hline Pintera Exteris & & & & & & & & & & & & & & & & & & & & & & & & & & & & & \\
\hline
\end{tabular}

Figura 2

Cronograma de Gantt do empreendimento

Fonte: Dados da construtora, 2016. 
Valeriano (2001) indica que os prazos são contenções comuns para se obter o sucesso, sendo preciso controlar e estimar todas as atividades durante todo o processo executivo. Conforme Limmer (2013), utilizando-se de cronogramas, é feito o controle dos prazos e de todos os recursos necessários para que possa se objetivar a determinação de erros nos prazos de realização, quando comparados ao prazo estabelecido inicialmente; para explorar os motivos dos erros e as consequências relacionadas aos prazos e custos e para ordenar formas de reparos necessários no decorrer de toda a execução. E é através da visão de transformação que se otimiza cada etapa, independentemente das outras etapas envolvidas na produção do projeto (Romero \& Andery, 2016).

Tomou-se como base o avanço da obra e o cronograma de Gantt, sendo possível realizar o gráfico previsto $\times$ realizado, delimitando assim, o progresso real da obra, como pode ser visto na Figura 3. Observou-se que nos meses de maio, junho e julho, a linha do realizado condiz com a linha do previsto, ou seja, o serviço estava em dia. Porém, em agosto e setembro, a obra teve um pequeno atraso. Segundo informações colhidas com o gestor responsável, a obra foi dividida em dois módulos: módulo 1 e módulo 2. Para realizar-se o módulo 1 da obra, fez-se necessário um repasse do financiamento da Caixa Econômica Federal, porém, houve um atraso neste. Devido a esse adiamento, a obra foi replanejada, de modo a não prejudicar o prazo final de entrega, como observado ainda na Figura 3. O gestor então, optou por concentrar a equipe de produção no módulo 1, uma vez que neste primeiro módulo há a maior concentração de atividades. Portanto, ao concentrar a equipe neste, o módulo 2 ficou com menos atividades, para que não ocorra outros atrasos na obra. 


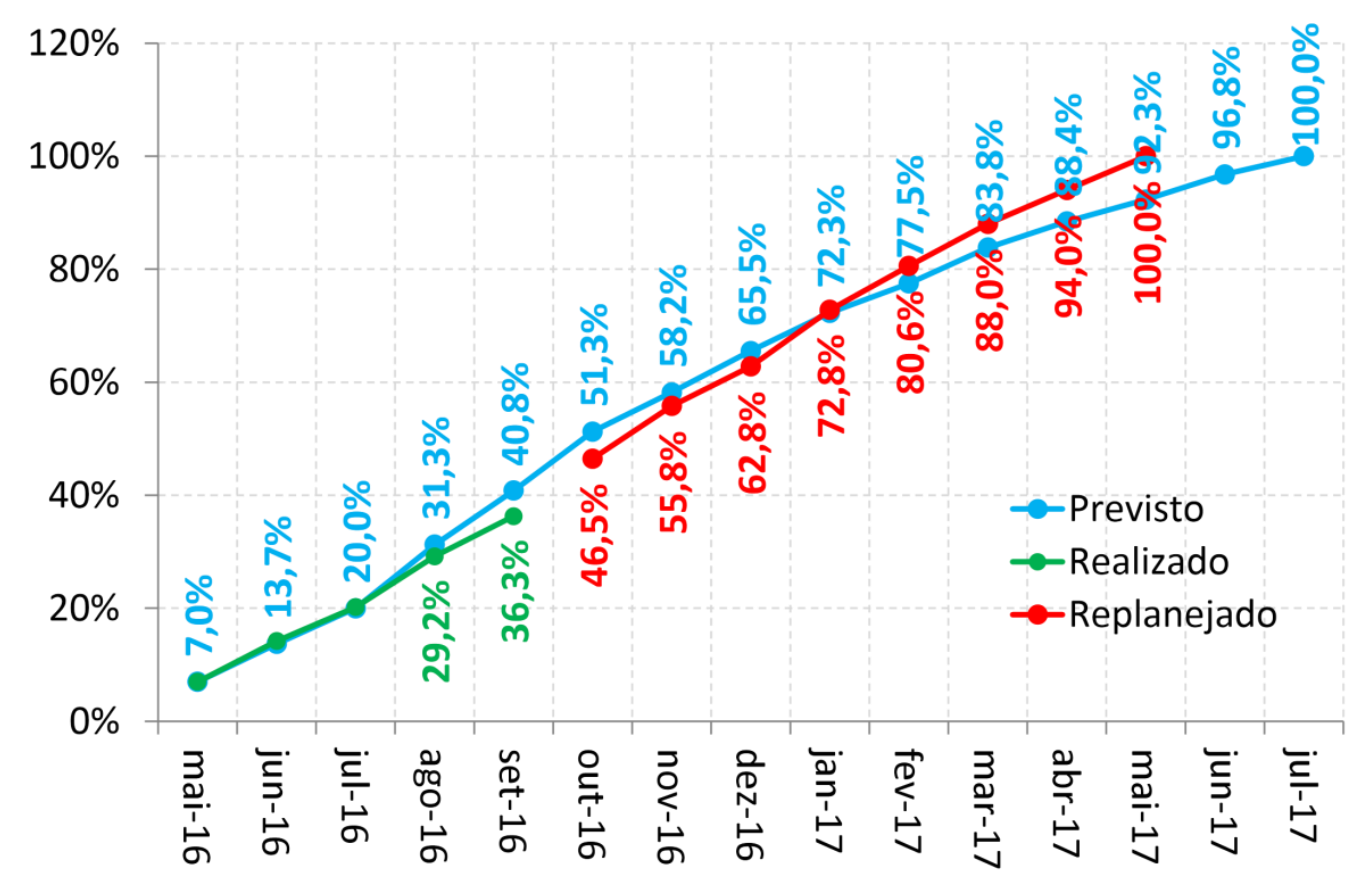

\section{PRAZO DO CLIENTE}

\section{Figura 3}

Previsto $\times$ Realizado

Fonte: Dados da construtora

Mattos (2010) conclui que esse tipo de controle é visualmente atraente, fácil de ser implementado e pode ser usado nas reuniões com as equipes de campo. Através destas informações é possível identificar as técnicas aplicadas neste planejamento, e é perceptível que estas são eficientes, visto que o Lean Construction analisa todos os processos, fluxos e atividades de construção, procurando sempre o real valor agregado de cada fase dos diversos processos envolvidos (Ferreira, 2003). Desta forma, Romero e Andery (2016) descrevem que a perfeição deve ser o propósito constante de todos os envolvidos norteando todos os esforços da empresa.

Adicionalmente, Valeriano (2001) define essa gestão do tempo como uma metódica organização de um cronograma e no ponderado domínio do mesmo, para que assim o projeto elaborado chegue ao término no prazo previsto. A administração do tempo do projeto, segundo o Project Management Institute - PMI, (2008), compreende parâmetros (duração, tamanho, complexidade, etc.) que são de suma importância para gerir o preciso término de um projeto. 
Ainda, conforme a Figura 3 pode-se observar que a velocidade de produção (VP) média é igual a 7,3\%. De acordo com Másculo \& Vidal et al. (2011), Ford ${ }^{1}$ afirmava que o rendimento de uma seção era calculado, pelo número de peças produzidas pelo número de horas de trabalho. Portanto, o resultado de $\mathrm{VP}_{\text {médio }}$ foi obtido por meio do seguinte cálculo: utilizando-se do valor do realizado do último mês, dividindo-se pelo número dos meses trabalhados. Com este resultado, podemos concluir que a equipe de produção está utilizando mais que a metade de sua eficácia.

$$
\frac{36,3 \%}{5}=7,26 \% \quad 7,26 \%>5,00 \% \text { (metade da eficácia) }
$$

Esse valor é um indicador capaz de medir os resultados que surgem do conceito TPM (Manutenção Produtiva Total) que busca a melhoria contínua dos processos produtivos. Assim, quando o desempenho de produção está abaixo do padrão satisfatório, o TPM atua no sentido de buscar soluções e corrigir problemas que geram perdas e prejuízos (Silva \& Resende, 2013). Ou seja, uma empresa de construção civil será mais competitiva, a partir da sua eficiência de produção. Portanto, a competitividade traduz-se como um planejamento racional das atividades de produção (Barros, 2005).

Conforme Figura 4, foi possível identificar no planejamento do empreendimento, um levantamento do quantitativo e tipo de serviços para execução de cada atividade e a elaboração de um quadro efetivo de mão de obra. Com esse controle, foi possível acompanhar a execução das atividades e a respectiva quantidade de mão de obra necessária em cada etapa.

${ }^{1}$ Henry Ford foi um empreendedor estadunidense, fundador da Ford Motor Company. 


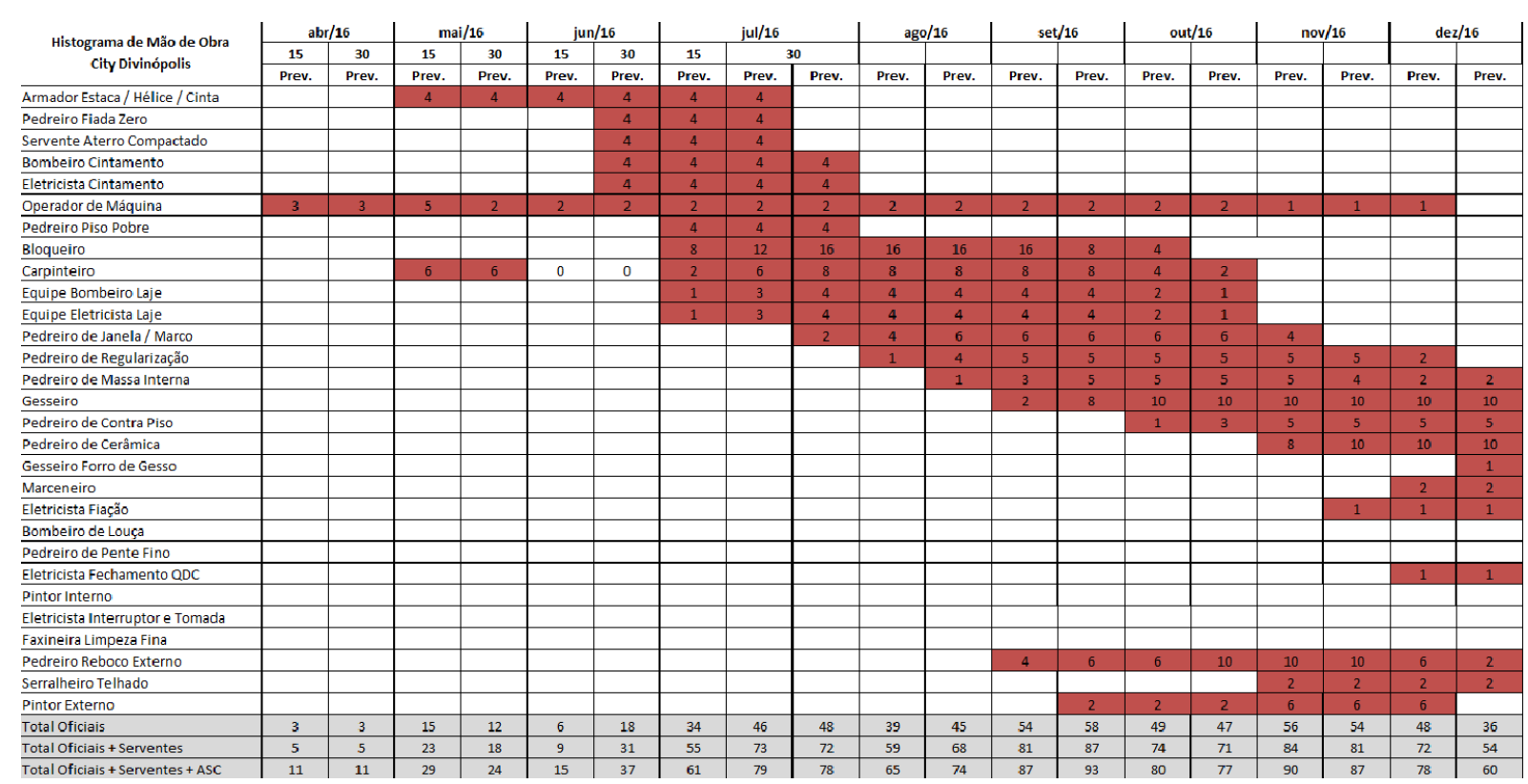

Figura 4

Histograma de mão de obra

Fonte: Dados da construtora, 2016

Limmer (2013) afirma que com cronogramas como esses, é possível verificar o controle da mão de obra, para analisar a regularidade e quais os tipos necessários, conforme fase da obra ou categoria, quantidade e consumo em cada atividade, relacionado ao planejamento inicial para a demanda que foi proposta inicialmente.

Souza (2000) destaca a importância de que a cada semana, se faça a estimativa da quantidade de operários e, dentre estes, quantos ficarão alojados no canteiro.

Para auxiliar esta estimativa, podem-se usar tabelas de simples visualização, as quais fornecem uma ideia de equipes médias envolvidas em cada tipo de serviço.

Ficou evidente que estão presentes no empreendimento mecanismos pertinentes à filosofia Lean, como ilustrado na Figura 5.

A obra segue pontualmente itens necessários a uma boa gestão, controlando, gerindo e aperfeiçoando todas as atividades projetadas e executadas. 


\section{Filosofia Lean Construction}

\begin{tabular}{|c|c|}
\hline Eliminação de desperdícios & Utilização do Just in time, $P D C A$ \\
\hline Fluxo contínuo & Processos continuamente aperfeiçoados \\
\hline Administração do tempo & Utilização do Cronograma de Gantt \\
\hline Melhorias contínuas & PDCA \\
\hline Aplicação de técnicas & Previsto $\times$ Realizado \\
\hline Controle da Obra & Cronograma de materiais, equipamentos e mão de obra \\
\hline Filosofia $5 \mathrm{~S}$ & Autodisciplina, limpeza, conservação e manutenção no canteiro de obra \\
\hline $\begin{array}{l}\text { Controle de custos, prazos e } \\
\text { qualidade }\end{array}$ & Reuniões realizadas todo mês com a técnica Previsto $\times$ Realizado \\
\hline
\end{tabular}

\section{Figura 5}

Comparativo entre a Filosofia Lean e o adotado na obra Fonte: Autoria Própria

Romero e Andery (2016) declaram que projetos bem-sucedidos são aqueles que são realizados dentro do orçamento e prazo previstos, com qualidade e dentro das perspectivas das partes interessadas.

Diante disso, Souza e Cabette (2014) enfatizam que a implementação do Lean Construction deve ser entendida como uma filosofia que tem por objetivo lapidar acima de tudo os processos de gestão e produção, porém, o sucesso desta prática depende do comprometimento da gerência, das necessidades da obra, do treinamento dos funcionários e de todos os envolvidos no processo. Ou seja, as atividades devem ser centradas no pensamento enxuto, mantendo o controle intenso da produção, possuindo como objetivo chave a melhoria na redução de custo e duração de cada etapa (Romero \& Andery, 2016).

$\mathrm{Na}$ visita in loco o gestor responsável explicou cada fase do canteiro de obras, tornando possível visualizar a utilização dos onze princípios elaborados por Koskela.

A Tabela 1 apresenta exemplos reais de utilização destes princípios na obra em estudo, o que já era esperado. 


\section{Tabela 1}

Exemplos reais de utilização dos princípios do Lean.

\begin{tabular}{|c|c|}
\hline $\begin{array}{l}\text { Princípios da Gestão de } \\
\text { Processos }\end{array}$ & Exemplo na Obra \\
\hline $\begin{array}{l}\text { Redução das atividades que não } \\
\text { agregam valor }\end{array}$ & $\begin{array}{c}\text { Arranjo físico da obra, ou seja, foi introduzida uma logística } \\
\text { interna, minimizando as distâncias entre os materiais, } \\
\text { equipamentos e local de utilização. }\end{array}$ \\
\hline $\begin{array}{l}\text { Aumentar o Valor do Produto } \\
\text { através da Consideração das } \\
\text { Necessidades do Cliente }\end{array}$ & $\begin{array}{l}\text { Implantação do sistema de qualidade, definindo tolerância de } \\
\text { aceitação de serviço, para liberação da próxima etapa. }\end{array}$ \\
\hline Reduzir a variabilidade & $\begin{array}{l}\text { Padronização dos processos de execução de serviços e } \\
\text { recebimento de materiais com inspeções, evitando falhas e } \\
\text { erros no planejamento e execução de serviços. }\end{array}$ \\
\hline Reduzir o tempo de ciclo & $\begin{array}{c}\text { Redução do tempo que envolve o processamento, inspeção, } \\
\text { espera, e movimentação da atividade. }\end{array}$ \\
\hline $\begin{array}{l}\text { Simplificar através da Redução do } \\
\text { Número de Passos ou Partes }\end{array}$ & $\begin{array}{l}\text { Utilização de elementos pré-fabricados, reduzindo } \\
\text { etapas para a execução de um elemento da edificação. }\end{array}$ \\
\hline Aumentar a Flexibilidade de Saída & $\begin{array}{c}\text { Possibilidade de mudanças, para atender às necessidades do } \\
\text { consumidor. }\end{array}$ \\
\hline $\begin{array}{l}\text { Aumentar a Transparência do } \\
\text { Processo }\end{array}$ & $\begin{array}{c}\text { Dispositivo de visualização e comunicação no canteiro, } \\
\text { indicando prazos e metas. }\end{array}$ \\
\hline $\begin{array}{l}\text { Foco no Controle de todo o } \\
\text { Processo }\end{array}$ & $\begin{array}{l}\text { Identificação dos desperdícios que ocorreram, ou que possam } \\
\text { ocorrer. }\end{array}$ \\
\hline $\begin{array}{l}\text { Estabelecimento de Melhoria } \\
\text { Contínua ao Processo }\end{array}$ & $\begin{array}{l}\text { Procedimentos de ação corretiva e preventiva, identificando os } \\
\text { problemas e as possíveis causas. }\end{array}$ \\
\hline $\begin{array}{l}\text { Balanceamento da Melhoria dos } \\
\text { Fluxos com a Melhoria das } \\
\text { Conversões }\end{array}$ & Organização dos estoques e fluxo dos materiais. \\
\hline $\begin{array}{l}\text { Aprender com Referências de } \\
\text { Ponta } \\
\text { (Benchmarking) }\end{array}$ & $\begin{array}{c}\text { Realização de práticas utilizadas em outras obras, para que } \\
\text { possam ser melhorados. }\end{array}$ \\
\hline
\end{tabular}

Fonte: Autoria Própria

Camera, Castro \& Campos (2015) salientam que com o aumento da transparência dos processos, os erros ficam mais fáceis de serem identificados no sistema de produção, ao mesmo tempo em que aumenta a disponibilidade de informações necessárias para a execução de tarefas, facilitando o trabalho. Assim sendo, o controle e execução de uma obra são tarefas sérias, que podem resultar em lucro ou prejuízo para a empresa.

De acordo com a Tabela 2, que apresenta o custo por $\mathrm{m}^{2}$ do empreendimento, foi possível calcular o custo orçado e projetado da obra. O ideal é que o valor para o custo projetado seja menor que o valor para o custo orçado. Para encontrar a economia prevista, dividiu-se o custo projetado pelo custo orçado. Quanto maior o resultado, melhor economia a obra estará tendo. 
Até o momento, a construção do empreendimento está com 1,00\% de economia projetada em relação ao orçado inicialmente.

- Custo orçado: 192 unidades $\times 45 \mathrm{~m}^{2}$ por apartamento $\times \mathrm{R} \$ 1.427,79=\mathrm{R} \$$ $12.336 .105,60$.

- Custo projetado: 192 unidades $\times 45 \mathrm{~m}^{2}$ por apartamento $\times \mathrm{R} \$ 1.406,90=\mathrm{R} \$$ 12.155.616,00.

$\frac{R \$ 12.155 .616,00}{R \$ 12.336 .105,60}=1,00 \%$ de economia

ANÁLISE FINANCEIRA (R\$)

OBRA

IC (índice

de

\begin{tabular}{|c|c|c|}
\hline Custo por $\mathbf{m}^{2}$ privativo s/Taxa Adm (Orçado) & $\mathrm{R} \$ 1.427,79$ & $\begin{array}{c}\text { construção) } \\
\text { - OBRA }\end{array}$ \\
\hline Custo por $\mathbf{m}^{\mathbf{2}}$ privativo s/Taxa Adm (Projeção) & $\mathrm{R} \$ 1.406,90$ & $1,00 \%$ \\
\hline
\end{tabular}

\section{Tabela 2}

Custo por $\mathrm{m}^{2}$ privativo ${ }^{2}$

Fonte: Dados da construtora, 2016

Quando se necessita de uma estimativa de fundos monetários para cumpriremse determinadas operações do projeto, desenvolve-se o procedimento de estimar custos (PMI, 2008). Para a indicação preliminar do que irá ser gasto em uma obra, tem-se: projeto finalizado daquilo que será construído e valores sempre atualizados dos equipamentos e mão de obra necessários (Borges, 2010). Nesse contexto, Hirschfeld (2005) ressalta que é necessária uma conscientização dos proprietários das obras para que o orçamento seja bem controlado, no que diz respeito, por exemplo, à alteração de projeto após o início das obras, supervisão de um profissional capacitado, mão de obra especializada. No entanto, Valeriano (2001) sugere uma gestão de custos para garantir o término do projeto observando todo o orçamento, que compreende em três processos: levantar gastos para ponderar custos, orçamentação e o controle desses custos.

Durante a visita, foi perceptível a qualidade da obra, que utiliza do sistema de alvenaria estrutural, em que as paredes são feitas de blocos de concreto, que, além de vedar a casa, forma a estrutura da construção. O desempenho deste sistema depende da qualidade dos materiais empregados e da sua produção adequada. As Figuras 5, 6 e 7 demonstram essa característica na obra.

\footnotetext{
${ }^{2} \mathrm{M}^{2}$ privativo é a área do imóvel de uso exclusivo de seu proprietário, agregando tudo o que é privativo ao apartamento no edifício, incluindo vaga de garagem e cômodos de despejo. É delimitada pela superfície externa das paredes.
} 


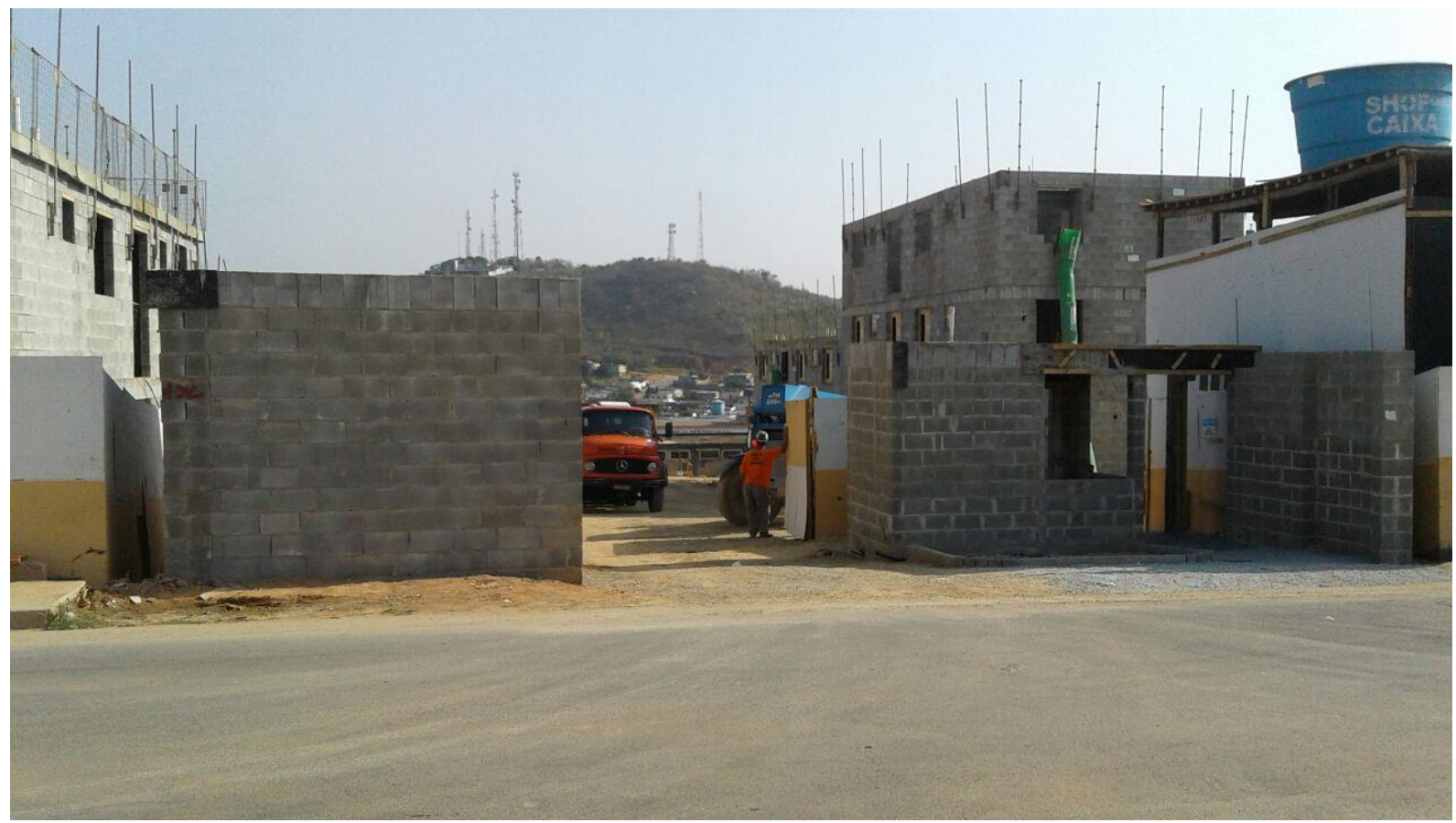

Figura 5

Fachada do empreendimento.

Fonte: Construtora (Setembro, 2016).

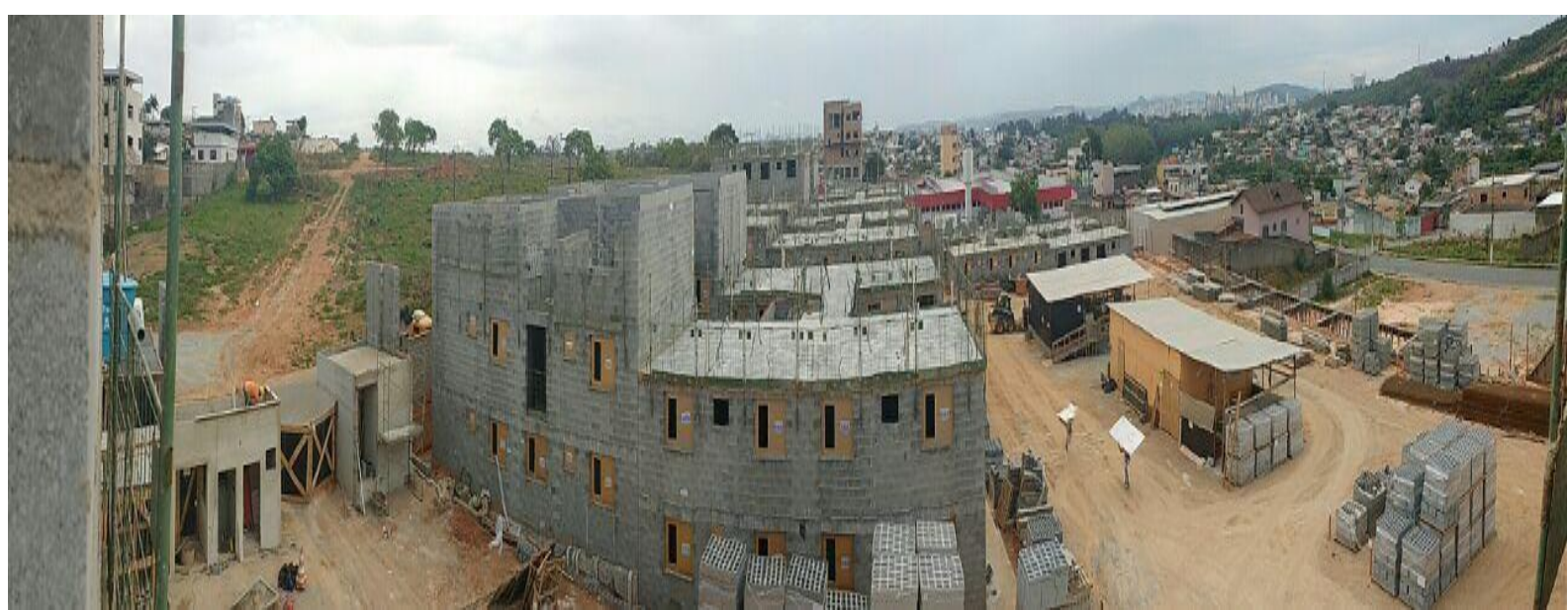

Figura 6

Visão panorâmica do empreendimento.

Fonte: Construtora (Outubro, 2016). 


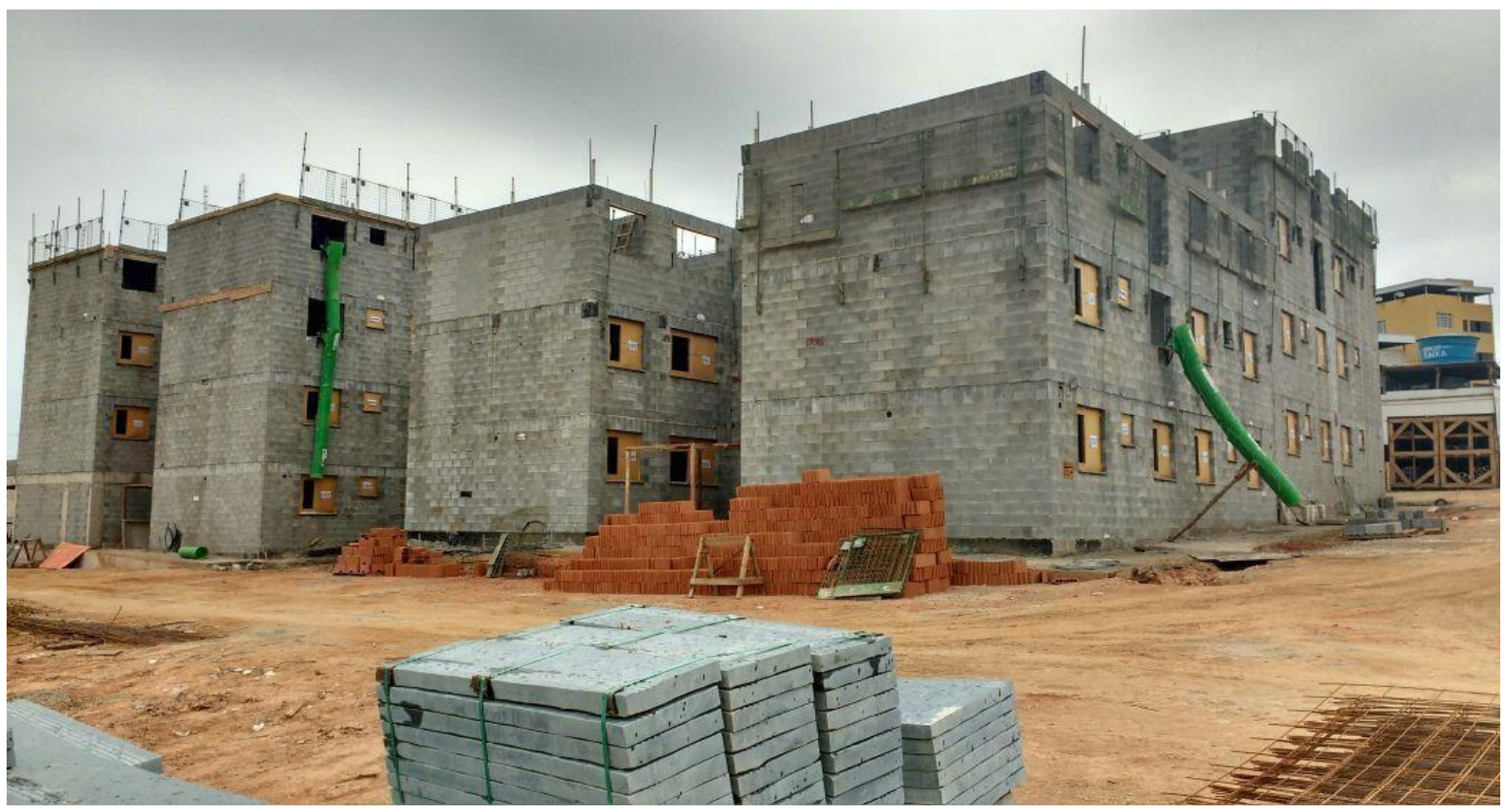

Figura 7

Elevação dos prédios.

Fonte: Construtora (Outubro, 2016).

Conforme Falconi (2014) a qualidade se faz presente quando um cliente recebe seu serviço ou produto no prazo estipulado, de modo a acrescer confiança, acessibilidade e segurança, suprindo as necessidades solicitadas. Nota-se que a garantia da qualidade tem como critério, a eliminação de 100\% (cem por cento) das falhas e uma busca incessante por nenhum defeito. Verifica-se assim no PMBOK (4 $4^{\text {a }}$ ed. - 2008) que o gerenciamento da qualidade do projeto, abrange todas as atividades, processos, objetivos e responsabilidades, de maneira que o projeto em questão venha a satisfazer toda e qualquer necessidade para as quais o mesmo foi proposto.

\section{Considerações Finais}

Por meio da realização deste trabalho, percebeu-se a grande necessidade de melhorar cada vez mais a gestão dos processos produtivos dentro das construtoras, principalmente em empreendimentos residenciais com um grande número de unidades habitacionais.

A implementação da filosofia Lean Construction, ocorreu inicialmente em atividades isoladas, porém, no final pode-se avaliar a mesma como um todo. Concluiuse, portanto, que ao implementar os conceitos da construção enxuta na obra utilizada 
como estudo de caso, a construtora foi beneficiada no aumento da produtividade, na redução dos dispêndios e desperdícios, na redução no prazo total de entrega do produto ao cliente, na redução da mão de obra, na melhor organização do canteiro de obras e na maior satisfação dos funcionários e cliente.

Um ponto importante que merece destaque é a questão das diretrizes propostas por cada construtora, uma vez que o sucesso da implantação de uma nova técnica de planejamento depende significativamente da sua organização, característica e conjuntura, de forma a priorizar as atividades da obra e as necessidades de melhorias como um todo.

O artigo contribuiu para a melhor percepção da gestão e planejamento de empreendimentos com essa tipologia, utilizando e aperfeiçoando novas técnicas de planejamento. Notou-se que a hipótese proposta inicialmente foi comprovada, mesmo no tocante às dificuldades, pois a filosofia Lean Construction, conseguiu otimizar os processos na obra avaliada. Em acréscimo, verificou-se que o maior ganho foi o fato de se conseguir uma considerável diminuição ou controle dos gastos, evitando qualquer desperdício possível, reduzindo o prazo de entrega do empreendimento e mantendo a qualidade do produto.

Visto que o setor da construção civil é repleto de novidades e contratempos, recomenda-se para futuros trabalhos dentro da temática, novos estudos englobando a execução completa de uma obra nesta mesma tipologia (empreendimento multifamiliar), avaliando os impactos dos custos e prazos totais, pois sabe-se que este artigo apresentado é um exemplo que pode ser melhorado, de acordo com as necessidades do setor. Assim, considera-se justificado o grau de importância do presente artigo, considerando alcançados os objetivos propostos inicialmente.

\section{Referências}

Azevedo, M. J., Barros, J. P., Neto., \& Nunes, F. R. M. (2010). Análise dos aspectos estratégicos da implantação da Lean Construction em duas empresas de construção civil de Fortaleza - CE. Anais do Simpósio de Administração da Produção, Logística e Operações Internacionais, São Paulo, SP, Brasil, 13.

Ballou, R. H. (2006). Gerenciamento da cadeia de suprimentos/logística empresarial. ( $5^{\mathrm{a}}$ ed.). Porto Alegre: Bookman. 
Barros, E. S. (2005). Aplicação da lean construction no setor de edificações: um estudo multicaso. (Dissertação de Mestrado em Engenharia de Produção, Universidade Federal de Pernambuco, Recife, PE, Brasil).

Borges, A. C. (2010). Prática das pequenas construções. (6a ed.). São Paulo: Blucher.

Camera, E., Castro, M. D. G., \& Campos, R. (2015). Princípios e Ferramentas da Lean Construction: Uma comparação entre empresas. Anais do Congresso Brasileiro de Engenharia de Produção. Ponta Grossa, PR, Brasil, 5.

Costa, Jr., \& Luiz, E. (2008). Gestão em processos produtivos. (1a ed.). Curitiba: Ibpex.

Dennis, P. (2008). Produção lean simplificada. (2a ed.). Porto Alegre: Bookman.

Falconi, V. (2014). TQC controle da qualidade total: no estilo japonês. (9a ed.). São Paulo: INDG Tecnologia e Serviços LTDA.

Ferreira, F. M. P. F. R. (2003). A Contribuição do modelo lean construction às técnicas de programação CPM na indústria da construção civil. Boletim Técnico da Faculdade de Tecnologia de São Paulo, 14, 28-39.

Gil, A. C. (2008). Métodos e técnicas de pesquisa social. (6a ed.). São Paulo: Atlas.

Hirschfeld, H. (1987). Planejamento com PERT e CPM e análise do desempenho. (9a ed.). São Paulo: Atlas.

Koskela, L. (1992) Application of new production philsophy to construction industry. Stanford: Cife, Technical Report.

LEAN INSTITUTE. Lean Institute Brasil. Disponível em: $<$ http://www.lean.org.br/default.aspx>.

Limmer, C. V. (2003). Planejamento, orçamentação e controle de projetos de obras. (1a ed.). Rio de Janeiro: LTC.

Lorenzon, I. A., \& Martins, R. A. (2006). Discussão sobre a medição de desempenho na Lean Construction. Anais do Simpósio de Engenharia de Produção, Bauru, SP, Brasil, 13.

Másculo, F. S., \& Vidal, M. C (orgs.). n/a et. al. (2011). Ergonomia: Trabalho adequado e eficiente. Rio de Janeiro: Elsevier: ABEPRO.

Mattos, A. D. (2010). Planejamento e controle de obras. (1a ed.). São Paulo: Pini LTDA.

PMI - Project Management Institute. (2008). Um guia do conhecimento em gerenciamento de projetos- Guia PMBOK@. (4a ed.) Newtown Square, Pennsylvania: Project Management Inst-id. 
Romero, F., \& Andery, P. (2016) Gestão de mega projetos: Uma abordagem lean. (1a ed.). Rio de Janeiro: Brasport.

Sales, A. L. F., Barros, J. P., \& Neto, Almino, I. (2004). A gestão dos fluxos físicos nos canteiros de obras focando a melhoria nos processos construtivos. Anais da Conferência Latino-Americana de Construção Sustentável, Encontro Nacional De Tecnologia Do Ambiente Construído, São Paulo, SP, Brasil 10.

Silva, L. D. S., \& Resende, A. A. (2013). Manutenção Produtiva Total (TPM) como ferramenta para melhoria da eficiência global de equipamento (OEE). Anais do Encontro Nacional de Engenharia de Produção, Salvador, BA, Brasil, 33.

Souza, B. C., \& Cabette, R. E. S. (2014). Gerenciamento da construção civil: estudo da aplicação da "lean construction" no Brasil. Revista Gestão \& Tecnologia, 2(1), 21-26.

Tonin, L. A. P.; Schaefer, C. O. (2013). Diagnóstico e Aplicação da Lean Constructionem Construtora. Anais do Encontro Nacional de Engenharia de Produção, Salvador, BA, Brasil, 33.

Valeriano, D. L. (2001). Gerenciamento estratégico e administração por projetos. (1a ed.). São Paulo: Makron Books.

Wiginescki, B. B. (2009). Aplicação dos princípios da construção enxuta em obras pequenas e de curto prazo: um estudo de caso. (Dissertação de Mestrado em Construção Civil, Universidade Federal do Paraná, Curitiba, PR, Brasil). 